\title{
Knowledge and Attitude of Pharmacy Students Regarding Geriatric Care: Questionnaire-Based Analysis in Malaysia
}

\author{
Ali Qais Blebil (D) ${ }^{1,2}$, Juman Abdulelah Dujaili (iD ${ }^{1,2}$, Ali Haider Mohammed ${ }^{1,2}$, \\ Kaeshaelya Thiruchelvam ${ }^{3}$, Shaun Lee $\mathbb{D}^{1}$, Ramadan Elkalmi $\mathbb{D}^{4}$, Yee Chang Soh ${ }^{5}$, Audrey Yong $\mathbb{D}^{6}$, \\ Rohullah Roien $\mathbb{1 D}^{7}$ \\ 'School of Pharmacy, Monash University Malaysia, Bandar Sunway, Selangor, Malaysia; ${ }^{2}$ Department of Pharmacy, Al Rafidain University College, \\ Baghdad, I000I, Iraq; ${ }^{3}$ School of Pharmacy, International Medical University, Bukit Jalil, Kuala Lumpur, Malaysia; ${ }^{4}$ Department of Pharmacology, Faculty \\ of Medicine, Sabha University, Sabha, Libya; ${ }^{5}$ Global Public Health, Jeffrey Cheah School of Medicine and Health Sciences, Monash University Malaysia, \\ Bandar Sunway, Malaysia; ${ }^{6}$ Faculty of Pharmacy, Mahsa University, Selangor, Malaysia; ${ }^{7}$ Medical Research Centre, Kateb University, Kabul, I004, \\ Afghanistan \\ Correspondence: Rohullah Roien, Medical Research Centre, Kateb University, Kabul, I004, Afghanistan, Tel +93 785454093, Email rohullahroien@kateb.edu.af
}

Introduction: There is a predicted growth of up to $17 \%$ in an older adult of Malaysian above 60 years of age by 2040 . This will increase the workload of almost every healthcare provider to ensure optimal geriatric care.

Purpose: This study aimed to assess pharmacy students' knowledge and attitudes towards geriatric pharmacy education and older patients to determine their preparation in delivering appropriate medical care to the geriatric population.

Methods: Self-administered questionnaires were distributed among pharmacy students in different Malaysian universities. The survey included several sections to assess multiple aspects such as sociodemographic information, assessment of knowledge using a validated 28-item Geriatric Knowledge Assessment Scale (GKAS), and attitudes towards geriatrics education.

Results: The response rate was around $70 \%$ of the respondents. The mean ( \pm standard deviation) age of the cohort was $22.28( \pm 1.12)$ years. Despite around $78 \%$ of pharmacy students claiming that their knowledge of geriatric care is adequate, their GKAS score showed that only around $20 \%$ have high geriatric knowledge. Around $80 \%$ of them showed a positive attitude on the importance of taking courses focused on geriatric care and demonstrated interest to further knowledge and training in geriatric care. However, more than half of the students were uncertain of their answers towards their attitudes regarding older patients.

Conclusion: Given the growing role of pharmacists in the ageing population, this study highlights the importance of geriatric care education among potential pharmacists. Therefore, we urge the need to improve/develop geriatrics education and training into the pharmacy curriculum to ensure sufficient preparation for actual practice after graduation.

Keywords: geriatric care, older adult, pharmacy students, knowledge, attitude, Malaysia

\section{Introduction}

Global demographic trends predict an exponential increase in the older adult population aged 60 and above in most countries worldwide by $2050 .{ }^{1}$ In Malaysia, the population growth of the older adults above 60 years has outpaced that of the young, doubling from approximately 1 million people to over 2.2 million people between 1991 and $2010 .^{2}$ This gap is expected to extend further over time, with a predicted rise to 7 million $(\sim 17.6 \%)$ of the expected Malaysian population of 40 million people by $2040 .^{3}$

Population ageing increases the strain on existing healthcare systems as the older adults population is more likely to suffer from multiple comorbidities and tends to display a higher dependency and utilisation of healthcare services when compared to the young. ${ }^{4,5}$ Consequently, future healthcare professionals must be prepared sufficiently throughout their undergraduate degree programs to recognise, assess and manage the challenging healthcare needs of the older adult 
population. In addition, it is also essential that the communication skills of future healthcare professionals are strengthened sufficiently. Hence, they will be able to educate older adult patients, promote health literacy, respond efficiently to any communication barriers, or empathise appropriately with their patient's health difficulties. ${ }^{6}$

Some of the health difficulties unique to the older adult population may include decreasing manual dexterity, memory impairment, hearing impairment and other age-related perception changes. ${ }^{7}$ These barriers can play a prominent role in impacting an older adult patient's treatment adherence behaviours and may directly affect the type and level of healthcare provided. Additionally, at least half of the global older adult population has been found to suffer from three or more chronic diseases, resulting in an increasingly challenging environment to provide optimal care. ${ }^{8}$ Inappropriate medication use and polypharmacy are also common problems faced by older adults that will continue to dominate and burden the healthcare system heavily. ${ }^{9}$

In the past decade, limitations in medical, pharmacy, and nursing students' geriatric education and knowledge have been noted. ${ }^{10-15}$ However, significant effort has been made to expand and improve geriatric education in education programs related to these professional disciplines. Healthcare students need to be equipped with an adequate knowledge base about biological ageing and pharmacological and lifestyle management in older adults. Suitable education initiatives have taken place to prepare students in healthcare disciplines to deliver appropriate medical care. In pharmacy, these initiatives include introducing relevant standards and recommendations and enhancing the curriculum guide to support pharmacists' education of geriatric-specific medication to ensure safe and effective medication management for older adults. ${ }^{16,17}$

Currently, there is no published information regarding pharmacy students' attitudes towards geriatric patients in the Southeast Asia region, especially in Malaysia. Therefore, this is the first study conducted in Malaysia that aimed to assess the knowledge and attitudes among pharmacy students towards older adult patients and the geriatrics-focused course work within the pharmacy curriculum.

\section{Materials and Methods Study Design and Participants}

A cross-sectional survey was conducted at five different public and private universities in Malaysia between September and December 2018. The universities were selected according to preliminary approval conditions of the pharmacy school for each university. This study included final-year pharmacy students only. The selection was chosen to ensure those selected students had been exposed to geriatric care either in their course in the early years or through clinical rotations and placements. Year 1 to year 3 of the undergraduate programme were excluded from this study based on the fact that there might be a likelihood that they had not yet covered or been exposed to the concepts of geriatric care in their curriculum or had not yet been rostered for clinical rotations or placements. The sampling frame included all final-year (fourth year) pharmacy students enrolled full time at the participating universities during the study period. The number of enrolled students during the study period was obtained from the respective lecturer coordinators in each university. The study was conducted for 4 months, from 1st September 2018 to 31st December 2019.

\section{Study Instrument}

A pre-validated questionnaire was used as a data collection tool. It comprised three sections: a sociodemographic section, a knowledge assessment section using a validated 28-item Geriatric Knowledge Assessment Scale (GKAS), and a section assessing student attitudes towards geriatric care education and older patients. The GKAS measures geriatric knowledge in the areas of ageing disease, physical activity, drug therapy, and nutrition with scores marked as either correct or incorrect. ${ }^{18}$ The GKAS was chosen as an appropriate instrument of measure due to its good design being a multiplechoice questionnaire rather than a dichotomous instrument. It was also a psychometrically sound instrument that assessed students' professional knowledge of ageing in older adults. Scores in this section ranged from 0 to 28 based on correct responses. Each student received one mark for a correct response and a zero mark for an incorrect response. Each student received a final knowledge score that indicated the number of questions answered correctly, where a higher score indicated better knowledge of ageing in older adults. Item correct response rate was calculated for each student. 
The attitudes assessment section was divided into two parts. The first part was adapted from a previous study focused on health professionals' educational needs in geriatric care. ${ }^{19}$ The second part included ten statements used to determine the students' attitudes towards older adult patients. The selected statements were adopted from the Geriatrics Attitudes Survey developed at the University of California, Los Angeles. ${ }^{20}$ This part was a 10-item, 5-point Likert scale, starting from "Strongly disagree" to "Strongly agree", validated for measuring health care professionals' attitudes toward older people and geriatric patients. ${ }^{21-23}$ Positivity of attitude was assessed by taking into account the whole cohort's average total score. Students who had a total score, from the ordinal data, above the average were considered to have a positive attitude, while those who scored below the average were considered negative. Cronbach's alpha was used to check the reliability of the modified items. The alpha coefficient of the items was 0.71 . A draft was given to a group of pharmacy students (10) for feedback regarding the questionnaire validation.

\section{Data Collection and Analysis}

The principal investigator invited multiple schools/faculties from other universities to expand the survey distribution. After getting approval from the institutes interested in distributing the survey among their pharmacy students, the selfadministered questionnaires were distributed at the end of their lecture session. The purpose of the study was explained to the students using a participant information sheet. The students were assured that completing the questionnaire would not affect their grades in the course, and their participation was completely voluntary. In addition, all enrolled participants provided their implied consent form by answering and completing the survey. The students completed these questionnaires anonymously.

The collected data were encoded and analysed using IBM Statistical Package for the Social Sciences (SPSS) software version 26.0. All participants' answers were excluded from the study if they missed out $>20 \%$ of the questionnaires. Data analysis was carried out in the form of descriptive and inferential statistics. Subsequent questionnaires were presented in categories by frequencies, percentages and mean \pm standard deviation for descriptive analysis. Ethical approval for this study was granted by the Human Ethics Committee at Monash University, Malaysia (ID No: 15274).

\section{Results}

\section{Sociodemographic Characteristics}

A total of 311/444 students agreed to participate in this study (response rate $=70.0 \%$ ). The demographic characteristics in this study are shown in Table 1. The majority of students who participated in this study were female $(71.7 \%)$. In addition, many students who participated in this study still had living grandparents $(71.7 \%)$ and shared a close relationship with their grandparents $(74.3 \%)$.

Table I Demographic Characteristics of Pharmacy Students $(n=311)$

\begin{tabular}{|l|l|}
\hline & Respondent, $\mathbf{n}(\%)$ \\
\hline Age* (mean \pm standard deviation) & $22.28 \pm 1.12$ \\
\hline $\begin{array}{c}\text { Gender } \\
\text { Male }\end{array}$ & $66(21.2)$ \\
Female & $245(78.8)$ \\
\hline Living grandparents & \\
Yes & $223(71.7)$ \\
No & $88(28.3)$ \\
\hline Close and connected to grandparents* & \\
Yes & $228(74.3)$ \\
No & $79(25.7)$ \\
\hline
\end{tabular}

Note: $* \mathrm{~N}=307$ students and valid percent were considered. 
Table 2 Level of Knowledge of Pharmacy Students

About Geriatric Based on Geriatric Knowledge

Assessment Scale (GKAS) Score $(\mathrm{N}=3 \mathrm{II})$

\begin{tabular}{|l|l|}
\hline Level of Knowledge* & Frequency (\%) \\
\hline Low & $83(26.7)$ \\
Average & $167(53.7)$ \\
High & $61(19.6)$ \\
\hline
\end{tabular}

Note: *Level of knowledge was categorised to each participant based on the final knowledge score of GKAS.

\section{Knowledge and Attitude Toward Geriatric Care Education}

The level of knowledge about geriatric patient care among pharmacy students is in Table 2 . The majority of the students highlight that they have low to average knowledge about geriatric care. Only 61 students $(19.6 \%)$ highlight high geriatric care knowledge (Table 2).

The attitude of the pharmacy students regarding pharmacy education is recorded in Table 3 . The majority of the students $(89.2 \%)$ agree and strongly agree that taking a course focused on geriatric care is of great importance. Slightly above three quarters $(77.6 \%)$ of the students indicated that their knowledge of geriatric care is adequate. Similarly, a large portion of the students $(87.9 \%)$ showed interest in increasing their knowledge of geriatrics.

The attitude of the final-year students towards adult older patients is recorded in Table 4. Almost half of the students $(48.0 \%)$ are neutral in whether they would prefer to care for older or younger patients, though the remaining students $(18.7 \%)$ are more inclined towards caring for younger patients. Over half of the students (65.5\%) agree that older patients are less organised, and while they may not be contributing significantly to health care costs, over three quarters (78.5\%) of the students agree that society has to care for the older adult.

\section{Discussion}

This study is considered the first of its kind to evaluate pharmacy students' level of knowledge and attitude regarding geriatric care and older patients in Asia. Population ageing is increasing globally as well as in Malaysia. Hence, geriatric care education has become an essential subject that pharmacy schools should not neglect or ignore. ${ }^{24}$

The results of the GKAS showed that pharmacy students in Malaysia have average knowledge about geriatric care. Surprisingly, this score was higher than similar studies conducted among PharmD students in the US, a five-year programme compared to the 4-year bachelor's undergraduate programme studied by Malaysian students. ${ }^{18}$ The high knowledge score may be attributed to the geriatric-specific learning content and clinical experiential training that the participating universities have incorporated into their pharmacy curriculum. However, the knowledge scores fluctuated between the five individual institutes, likely due to the different levels of the geriatric education exposure of the various programs in those institutes. It is essential to provide foundational knowledge and skills that allow students to care for older patients.

Table 3 Pharmacy Students' Attitudes Regarding Geriatric Pharmacy Education $(\mathrm{N}=3 \mathrm{II})$

\begin{tabular}{|l|l|l|l|l|l|}
\hline Item & $\begin{array}{l}\text { Strongly Disagree, } \\
\mathbf{n}(\%)\end{array}$ & $\begin{array}{l}\text { Disagree, } \\
\mathbf{n}(\%)\end{array}$ & $\begin{array}{l}\text { Neutral, } \\
\mathbf{n}(\%)\end{array}$ & $\begin{array}{l}\text { Agree, } \\
\mathbf{n}(\%)\end{array}$ & $\begin{array}{l}\text { Strongly Agree, } \\
\mathbf{n}(\%)\end{array}$ \\
\hline $\begin{array}{l}\text { I.Importance of taking a course focused on } \\
\text { geriatric care }\end{array}$ & $5(1.6)$ & $1(0.3)$ & $27(8.8)$ & $164(53.4)$ & $110(35.8)$ \\
\hline 2.Adequacy of knowledge in geriatrics & $5(1.6)$ & $16(5.2)$ & $48(15.6)$ & $138(45.0)$ & $100(32.6)$ \\
\hline 3.Interest in increasing knowledge of geriatrics & $3(1.0)$ & $2(0.7)$ & $32(10.4)$ & $153(49.8)$ & $117(38.1)$ \\
\hline 4.Adequacy of training in geriatric care* & $6(2.0)$ & $17(5.6)$ & $43(14.1)$ & $138(45.4)$ & $100(32.9)$ \\
\hline
\end{tabular}

Note: $* \mathrm{~N}=304$. 
Table 4 Final-Year Pharmacy Students' Attitudes Regarding Older Adult Patients $(\mathrm{N}=3 \mathrm{I} \mathrm{I})$

\begin{tabular}{|c|c|c|c|c|c|c|}
\hline Items & Mean (SD) & $\begin{array}{l}\text { Strongly } \\
\text { Disagree (I), } \\
\text { No. (\%) }\end{array}$ & $\begin{array}{l}\text { Disagree } \\
\text { (2), No. } \\
(\%)\end{array}$ & $\begin{array}{l}\text { Neutral } \\
\text { (3), No. } \\
(\%)\end{array}$ & $\begin{array}{l}\text { Agree } \\
(4), \text { No. } \\
(\%)\end{array}$ & $\begin{array}{l}\text { Strongly } \\
\text { Agree (5), } \\
\text { No. (\%) }\end{array}$ \\
\hline $\begin{array}{l}\text { I.If I have the choice, I would rather see younger } \\
\text { patients than elderly ones. }(N=304)(\#)\end{array}$ & $2.8(0.93)$ & $26(8.6)$ & 75 (24.7) & $146(48.0)$ & $45(14.8)$ & $12(3.9)$ \\
\hline $\begin{array}{l}\text { 2.Medical care for the elderly uses up too many } \\
\text { human and material resources. }(\mathrm{N}=305)(+)\end{array}$ & $2.9(1.0)$ & $27(8.9)$ & 85 (27.9) & $101(33.1)$ & $80(26.2)$ & $12(3.9)$ \\
\hline $\begin{array}{l}\text { 3.As people grow older, they become less } \\
\text { organised and more confused. }(N=307)(-)\end{array}$ & $3.6(0.86)$ & $7(2.3)$ & $24(7.8)$ & $75(24.4)$ & $\begin{array}{l}167 \\
(54.4)\end{array}$ & 34 (II.I) \\
\hline $\begin{array}{l}\text { 4.Taking medical history from elderly patients is } \\
\text { frequently an ordeal. }(\mathrm{N}=306)(-)\end{array}$ & $2.6(0.87)$ & $7(2.3)$ & $33(10.6)$ & $129(4 \mid .5)$ & $\begin{array}{l}113 \\
(36.3)\end{array}$ & $24(7.7)$ \\
\hline $\begin{array}{l}\text { 5. Old people in general do not contribute much } \\
\text { to society. }(N=307)(+)\end{array}$ & $3.7(0.94)$ & $67(21.8)$ & I $24(40.4)$ & $84(27.4)$ & $29(9.4)$ & $3(1.0)$ \\
\hline $\begin{array}{l}\text { 6. Treatment of chronically ill old patients is } \\
\text { hopeless. }(\mathrm{N}=304)(+)\end{array}$ & $3.8(0.97)$ & $73(24.0)$ & $122(40.1)$ & $78(25.7)$ & $26(8.6)$ & $5(1.6)$ \\
\hline $\begin{array}{l}\text { 7.Old persons do not contribute their fair share } \\
\text { in paying for their healthcare }(N=305)(+)\end{array}$ & $3.7(0.87)$ & $59(19.3)$ & $116(38.0)$ & $110(36.1)$ & $18(5.9)$ & $2(0.7)$ \\
\hline $\begin{array}{l}\text { 8.In general, older people act too slowly for } \\
\text { modern society. }(N=304)(n)\end{array}$ & $3.4(0.99)$ & $50(16.4)$ & $84(27.6)$ & $116(38.2)$ & $50(16.4)$ & $4(1.3)$ \\
\hline $\begin{array}{l}\text { 9.Elderly patients appreciate medical care more } \\
\text { than younger patients. }(\mathrm{N}=305)(+)\end{array}$ & $3.5(0.93)$ & $9(3.0)$ & $25(8.2)$ & $119(39.0)$ & $\begin{array}{l}110 \\
(36.1)\end{array}$ & $42(13.8)$ \\
\hline $\begin{array}{l}\text { 10.It is society's responsibility to care for its } \\
\text { elderly patients. }(+)\end{array}$ & 4.I $(0.88)$ & $4(1.3)$ & $10(3.3)$ & $52(17.0)$ & $\begin{array}{l}126 \\
(41.2)\end{array}$ & $114(37.3)$ \\
\hline
\end{tabular}

Notes: A plus sign (+) after an item indicates that students had a positive attitude about that item, while a minus sign (-) indicates students had a negative attitude about that item. Sign (\#) indicates students were unsure about the item, having neither a positive nor negative attitude.

Abbreviation: SD, standard deviation.

The results also indicated that pharmacy students perceive the importance of having extensive knowledge in geriatric care and express interest in increasing knowledge. This is consistent with the findings of Holmes et al, which demonstrated that most students expressed the need to be trained more in geriatric care despite their current limited knowledge. ${ }^{25}$ The growing number of patients in older age with complex chronic illnesses requires equally knowledgeable personnel to tend to them. It is found that education in geriatric care is prioritised in postgraduate educations, such as master's and doctorate programmes, rather than undergraduate ones. However, fewer students usually pursue their studies until the doctorate level in the pharmaceutical field; thus, this lack of knowledge on geriatric care translates into the workplace. ${ }^{24}$ When knowledge is not shared at the undergraduate level, it is reflected in the workplace as most personnel still lack these skills. This supports the findings of a previous study that asserted how compulsory courses in geriatric education at all levels of pharmacy school are an essential part of the curriculum that has directly applicable lessons in the workplace. ${ }^{26}$

Moreover, interestingly, final-year pharmacy students showed a very positive attitude towards older adult patients. This result is consistent with other studies investigating pharmacy students' attitudes toward older adults. ${ }^{27-30}$ Based on previous findings, the appropriateness of care provided by the pharmacists might be determined via their attitudes toward this population. ${ }^{23}$ Most of the participants recruited in this study demonstrated a close connection to their grandparents and could account for the observed positive attitudes toward older patients. Previous studies found that exposing healthcare professional students to a geriatrics-care focussed-course improved their attitudes toward older patients. ${ }^{31-34}$ 
Participants somehow agreed that older adults might not contribute much to healthcare. However, their contribution towards healthcare in their younger years should not be dismissed, as it is reported that $43 \%$ of adults do not use their health insurance until their older adult years. ${ }^{35}$ This asserts the studies of De Geer et al, which indicate that society has to care for older adult patients. ${ }^{36}$ Furthermore, the higher chances of contracting chronic illnesses and lower chances of recovery lead to older adults appreciating healthcare more than, the younger population. Therefore, these sentiments should be reinforced in the early stages of pharmacy to improve personnel's knowledge of geriatric care and adopt a more cooperative and collaborative attitude when they come across geriatrics in further study or practice.

Additionally, pharmacy students agreed that geriatric patients are less organised and may fail to provide comprehensive information on their medical history. However, it is not a reason for them to receive negligent health care. ${ }^{37}$ There is a need to increase the knowledge of healthcare personnel in geriatric care, as this would improve the quality of healthcare administered to older adults. The current state of a patient should not be considered to measure whether they deserve optimum health care. Instead, the focus of health care should be on providing each patient with a fair chance at recovery and survival. However, it concerns to note how older adults are often given biased health care. ${ }^{38}$ When the health personnel feel that the older adult patient has well advanced in illness and would probably die, they would have a relaxed approach towards their treatment. ${ }^{39}$ Therefore, geriatric care and education must be prioritised to reduce the incidents of older adults being taken advantage of without any accountability. Instead of withholding resources in treatment and giving way to the older adult to fight for their wellbeing with limited resources, the attitude of the healthcare personnel should be channelled towards a more thoughtful approach. ${ }^{40}$ Educating potential pharmacists to have a positive attitude toward older patients is a critical step that helps to improve geriatric healthcare system as well as increase their survival rate.

Finally, the study has certain limitations. The sample size collected may have contributed to some recall bias in the survey answers, though the bias should be minimal with a $70 \%$ response rate. ${ }^{41}$ Additionally, the study did not account for work experience with the older patients outside of their educational activities, which may impact their knowledge and attitudes.

\section{Conclusion}

There is a necessity to increase the knowledge and attitude of the personnel on geriatric health care to improve the health care of the older adult patients and increase their chances of survival from chronic illnesses. Therefore, it is urged that faculties, schools, and pharmacy colleges in Malaysia reconsider implementing more comprehensive geriatrics-focused courses within their curriculum, for example, including a simulation and other teaching methods within the teaching activities. Furthermore, long-term observational studies are needed to assess the impact of implementing these courses on future graduates while pursuing their practice careers. In addition, making these courses as a compulsory component in the pharmacy accreditation program, courses with a more profound emphasis on geriatric care will be beneficial to equip the future generation of pharmacists in providing better medical care for geriatric patients in Malaysia.

\section{Acknowledgment}

The authors would like to acknowledge Sunil Shrestha, PhD Student, Monash University Malaysia for his critical review of the manuscript.

\section{Author Contributions}

All authors made a significant contribution to the work reported, whether that is in the conception, study design, execution, acquisition of data, analysis and interpretation, or in all these areas; took part in drafting, revising or critically reviewing the article; gave final approval of the version to be published; have agreed on the journal to which the article has been submitted; and agree to be accountable for all aspects of the work.

\section{Funding}

This research received no specific grant from any funding agency in the public, commercial or not-for-profit sectors. 


\section{Disclosure}

The authors report no conflicts of interest in this work.

\section{References}

1. United Nations. United nations department of economic and social affairs, population division. world population prospects: the 2015 revision. Technical Report. Working Paper No. ESA/P/WP; 2015:241.

2. Tey NP, Siraj SB, Kamaruzzaman SBB, et al. Aging in multi-ethnic Malaysia. Gerontologist. 2016;56(4):603-609. doi:10.1093/geront/gnv153

3. United Nations. World population prospects: the 2015 revision, key findings and advance tables. Department of Economic and Social Affairs, Population Division; 2015.

4. Rechel B, Grundy E, Robine J-M, et al. Ageing in the European Union. Lancet. 2013;381(9874):1312-1322. doi:10.1016/S0140-6736(12)62087-X

5. Rowe JW. Successful aging of societies. Daedalus. 2015;144(2):5-12. doi:10.1162/DAED_a_00325

6. American Society of Consultant Pharmacists. Geriatric pharmacy curriculum guide; 2015. Available from: http://catch-on.org/wp-content/uploads/ 2016/12/Pharmacy_Curriculum_Competency_Guide_ASCP_Final_2015.pdf. Accessed Jan, 2019.

7. Elsawy B, Higgins KE. The geriatric assessment. Am Fam Physician. 2011;83(1):48-56.

8. American Geriatrics Society Expert Panel on the Care of Older Adults with Multimorbidity. Guiding principles for the care of older adults with multimorbidity: an approach for clinicians. $J$ Am Geriatr Soc. 2012;60(10):E1-E25. doi:10.1111/j.1532-5415.2012.04188.x

9. Boult C, Christmas C, Durso SC, Leff B, Boult LB, Fried LP. Perspective: transforming chronic care for older persons. Acad Med. 2008;83 (7):627-631. doi:10.1097/ACM.0b013e3181782b14

10. Perrotta P, Perkins D, Schimpfhauser F, Calkins E. Medical student attitudes toward geriatric medicine and patients. Acad Med. 1981;56 (6):478-483. doi:10.1097/00001888-198106000-00003

11. Dutta A, Daftary M, Oke F, Mims B, Hailemeskel B, Sansgiry S. Geriatric education in U.S. schools of pharmacy: a snapshot. Consult Pharm. 2005;20(1):45-52. doi:10.4140/TCP.n.2005.45

12. Gilje F, Lacey L, Moore C. Gerontology and geriatric issues and trends in U.S. nursing programs: a national survey. J Prof Nurs. 2007;23(1):21-29. doi:10.1016/j.profnurs.2006.12.001

13. Gray SL, Elliott D, Semla T. Implications for pharmacy from the institute of medicine's report on health care workforce and an aging America. Ann Pharmacother. 2009;43(6):1133-1138. doi:10.1345/aph.1L589

14. Odegard PS, Breslow RM, Koronkowski MJ, Williams BR, Hudgins GA. Geriatric pharmacy education: a strategic plan for the future. Am J Pharm Educ. 2007;71(3):47. doi:10.5688/aj710347

15. Woolsey LJ. Physician assistant attitude and expressed intent to work with geriatric patients. Gerontol Geriatr Educ. 2007;28(1):61-78. doi:10.1300/J021v28n01_05

16. Accreditation Council for Pharmacy Education. Accreditation standards and guidelines for the professional program in pharmacy leading to the doctor of pharmacy degree; 2007. Available from: https://www.acpe-accredit.org/standards/default.asp. Accessed December 1, 2014.

17. Roche VF, Nahata MC, Wells BG, et al. Roadmap to 2015: preparing competent pharmacists and pharmacy faculty for the future. Combined report of the 2005-06 argus commission and the academic affairs, professional affairs, and research and graduate affairs committees. Am J Pharm Educ. 2006;70(5):S5. doi:10.5688/aj7005S05

18. Dacey M, McCloskey WW, Zeind C, et al. Development of a questionnaire to assess health profession students' knowledge of older adults. Curr Pharm Teach Learn. 2014;6(2):233-244. doi:10.1016/j.cptl.2013.11.003

19. Turner Goins R, Jane Gainor S, Pollard C, Melinda Spencer S. Geriatric knowledge and educational needs among rural health care professionals. Educ Gerontol. 2003;29(3):261-272. doi:10.1080/713844301

20. Reuben DB, Lee M, Davis JW Jr, et al. Development and validation of a geriatrics attitudes scale for primary care residents. J Am Geriatr Soc. 1998;46(11):1425-1430. doi:10.1111/j.1532-5415.1998.tb06012.x

21. Kishimoto M, Nagoshi M, Williams S, Masaki KH, Blanchette PL. Knowledge and attitudes about geriatrics of medical students, internal medicine residents, and geriatric medicine fellows. J Am Geriatr Soc. 2005;53(1):99-102. doi:10.1111/j.1532-5415.2005.53018.x

22. Lee M, Reuben DB, Ferrell BA. Multidimensional attitudes of medical residents and geriatrics fellows toward older people. J Am Geriatr Soc. 2005;53(3):489-494. doi:10.1111/j.1532-5415.2005.53170.x

23. Adkins DM, Mayhew SL, Gavaza P, Rahman S. Pharmacy students' attitudes toward geriatric nursing home patients. Am J Pharm Educ. 2012;76 (5):81. doi:10.5688/ajpe76581

24. Felton MA, Jarrett JB, Meyer SM. Geriatric care curriculum in US PharmD programs: what's happening? Curr Pharm Teach Learn. 2017;9 (3):504-509. doi:10.1016/j.cptl.2016.12.006

25. Holmes SD, Smith E, Resnick B, et al. Students' perceptions of interprofessional education in geriatrics: a qualitative analysis. Gerontol Geriatr Educ. 2020;41(4):480-493. doi:10.1080/02701960.2018.1500910

26. Zolezzi M, Sadowski CA, Al-Hasan N, Alla OG. Geriatric education in schools of pharmacy: students' and educators' perspectives in Qatar and Canada. Curr Pharm Teach Learn. 2018;10(9):1184-1196. doi:10.1016/j.cpt1.2018.06.010

27. Shepherd MD, Erwin G. An examination of students' attitudes toward the elderly. Am J Pharm Educ. 1983;47(1):35-38.

28. Sauer BL. Student-directed learning in a community geriatrics advanced pharmacy practice experience. Am J Pharm Educ. 2006;70(3):54. doi:10.5688/aj700354

29. Woelfel JA, Boyce E, Patel RA. Geriatric care as an introductory pharmacy practice experience. Am J Pharm Educ. 2011;75(6):115. doi:10.5688/ ajpe 756115

30. Chen AMH, Plake KS, Yehle KS, Kiersma ME. Impact of the geriatric medication game on pharmacy students' attitudes toward older adults. Am J Pharm Educ. 2011;75(8):158. doi:10.5688/ajpe758158

31. Green SK, Keith KJ, Pawlson LG. Medical students' attitudes toward the elderly. J Am Geriatr Soc. 1983;31(5):305-309. doi:10.1111/j.15325415.1983.tb04876.x

32. Wilson JF, Hafferty FW. Changes in attitudes toward the elderly one year after a seminar on aging and health. J Med Educ. 1980;55(12):993-999. doi:10.1097/00001888-198012000-00002 
33. Deary IJ, Smith R, Mitchell C, Maclennan WJ. Geriatric medicine: does teaching alter medical students' attitudes to elderly people? Med Edu. 1993;27(5):399-405. doi:10.1111/j.1365-2923.1993.tb00292.x

34. Duque G, Gold S, Bergman H. Early clinical exposure to geriatric medicine in second-year medical school students-the McGill experience. $J$ Am Geriatr Soc. 2003;51(4):544-548. doi:10.1046/j.1532-5415.2003.51166.x

35. Arkorful VE, Lugu BK, Hammond A, Basiru I, Afriyie FA, Mohajan B. Examining quality, value, satisfaction and trust dimensions: an empirical lens to understand health insurance systems actual usage. Public Organ Rev. 2021;1-19. doi:10.1007/s11115-020-00498-x

36. De Geer L, Fredrikson M, Tibblin AO. Frailty predicts 30-day mortality in intensive care patients: a prospective prediction study. Eur $J$ Anaesthesiol. 2020;37(11):1058-1065. doi:10.1097/EJA.0000000000001156

37. Persson HL, Lyth J, Wiréhn A-B, Lind L. Elderly patients with COPD require more health care than elderly heart failure patients do in a hospital-based home care setting. Int J Chron Obstruct Pulmon Dis. 2019;14:1569. doi:10.2147/COPD.S207621

38. American Geriatrics Society. American geriatrics society policy brief: COVID-19 and nursing homes. J Am Geriatr Soc. 2020;68(5):908-911. doi:10.1111/jgs.16477

39. Atmış V, Bahşi R, Öztorun HS, et al. Public awareness of geriatrics in the 50th year of geriatrics in Turkey. Eur J Geriatr Gerontol. 2019;1 (1):24-28. doi:10.4274/ejgg.galenos.2019.35

40. Niu S, Tian S, Lou J, et al. Clinical characteristics of older patients infected with COVID-19: a descriptive study. Arch Gerontol Geriatr. 2020;89:104058. doi:10.1016/j.archger.2020.104058

41. Draugalis JR, Plaza CM. Best practices for survey research reports revisited: implications of target population, probability sampling, and response rate. Am J Pharm Educ. 2009;73(8):142. doi:10.5688/aj7308142

Advances in Medical Education and Practice

\section{Dovepress}

\section{Publish your work in this journal}

Advances in Medical Education and Practice is an international, peer-reviewed, open access journal that aims to present and publish research on Medical Education covering medical, dental, nursing and allied health care professional education. The journal covers undergraduate education, postgraduate training and continuing medical education including emerging trends and innovative models linking education, research, and health care services. The manuscript management system is completely online and includes a very quick and fair peer-review system. Visit http://www.dovepress.com/testimonials.php to read real quotes from published authors.

Submit your manuscript here: http://www.dovepress.com/advances-in-medical-education-and-practice-journal 